\title{
Molecular characterization of Clonorchis sinensis secretory myoglobin: Delineating its role in anti-oxidative survival
}

Mengyu Ren ${ }^{1,2+}$, Lei He ${ }^{1,2+}$, Yan Huang ${ }^{1,2}$, Qiang Mao ${ }^{1,2}$, Shan Li ${ }^{1,2}$, Honglin Qu ${ }^{1,2}$, Meng Bian 1,2, Pei Liang ${ }^{3}$, Xueqing Chen ${ }^{1,2}$, Jinsi Ling ${ }^{1,2}$, Tingjing Chen ${ }^{1,2}$, Chi Liang ${ }^{1,2}$, Xiaoyun Wang ${ }^{1,2}$, Xuerong $\mathrm{Li}^{1,2^{*}}$ and Xinbing $\mathrm{Yu}^{1,2^{*}}$

\begin{abstract}
Background: Clonorchiasis is a globally important, neglected food-borne disease caused by Clonorchis sinensis (C. sinensis), and it is highly related to cholangiocarcinoma and hepatocellular carcinoma. Increased molecular evidence has strongly suggested that the adult worm of $C$. sinensis continuously releases excretory-secretory proteins (ESPs), which play important roles in the parasite-host interactions, to establish successful infection and ensure its own survival. Myoglobin, a hemoprotein, is present in high concentrations in trematodes and ESPs. To further understand the biological function of CsMb and its putative roles in the interactions of $C$. sinensis with its host, we explored the molecular characterization of CsMb in this paper.

Methods: We expressed CSMb and its mutants in E. coli BL21 and identified its molecular characteristics using bioinformatics analysis and experimental approaches. Reverse transcription PCR analysis was used to measure myoglobin transcripts of $C$. sinensis with different culture conditions. The peroxidase activity of CsMb was confirmed by spectrophotometry. We co-cultured RAW264.7 cells with recombinant CsMb (rCsMb), and we then measured the production of hydrogen peroxide $\left(\mathrm{H}_{2} \mathrm{O}_{2}\right)$ and nitric oxide $(\mathrm{NO})$ in addition to the mRNA levels of inducible nitric oxide synthase (iNOS), Cu-Zn superoxide dismutase (SOD1) and Mn superoxide dismutase (SOD2) in activated RAW264.7 cells.

Results: In the in vitro culture of adult worms, the transcripts of CsMb increased with the increase of oxygen content. Oxidative stress conditions induced by $\mathrm{H}_{2} \mathrm{O}_{2}$ increased the levels of CsMb transcripts in a dose-dependent manner. Furthermore, CsMb catalyzed oxidation reactions in the presence of $\mathrm{H}_{2} \mathrm{O}_{2}$, and amino acid 34 of CsMb played an essential role in its reaction with $\mathrm{H}_{2} \mathrm{O}_{2}$. In addition, $\mathrm{CsMb}$ significantly reduced $\mathrm{H}_{2} \mathrm{O}_{2}$ and $\mathrm{NO}$ levels in LPS-activated macrophages, and CSMb downregulated iNOS and SOD expression in activated macrophages.

Conclusion: The present study is the first to investigate the peroxidase activity of CsMb. This investigation suggested that $C$. sinensis may decrease the redox activation of macrophages by CsMb expression to evade host immune responses. These studies contribute to a better understanding of the role of CsMb in the molecular mechanisms involved in ROS detoxification by C. sinensis.
\end{abstract}

Keywords: Myoglobin, Clonorchis sinensis, Point mutation, Hydrogen peroxide, RAW264.7, Peroxidase activity

\footnotetext{
* Correspondence: xuerong2@mail.sysu.edu.cn; yuhxteam@163.com

${ }^{\dagger}$ Equal contributors

'Department of Parasitology, Zhongshan School of Medicine, Sun Yat-sen

University, 74 Zhongshan 2nd Road, Guangzhou, Guangdong 510080, China

${ }^{2}$ Key Laboratory for Tropical Diseases Control (Sun Yat-sen University),

Ministry of Education, 74 Zhongshan 2nd Road, Guangzhou, Guangdong

510080, China

Full list of author information is available at the end of the article
}

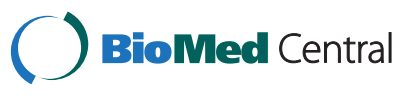

(C) 2014 Ren et al.; licensee BioMed Central Ltd. This is an Open Access article distributed under the terms of the Creative Commons Attribution License (http://creativecommons.org/licenses/by/4.0), which permits unrestricted use, distribution, and reproduction in any medium, provided the original work is properly credited. The Creative Commons Public Domain Dedication waiver (http://creativecommons.org/publicdomain/zero/1.0/) applies to the data made available in this article, unless otherwise stated. 


\section{Background}

Clonorchiasis is predominantly an endemic disease in countries and regions of eastern Asia. Approximately 35 million people are infected with this food-borne trematode, and more than 15 million people are infected with Clonorchiasis in China [1-3]. Chronic infections cause easy fatigue, abdominal pain, mechanical obstruction of the hepatobiliary duct, cholangiectasis and biliary stones [4]. Furthermore, C. sinensis has long been associated with cholangiocarcinoma in humans, and it has been classified as a group I carcinogen-metazoan parasite by the International Agency of Cancer Research of the World Health Organization [5]. Prior studies have demonstrated that adult liver flukes are able to survive in hosts for 20-25 years [6]. During long-term parasitism, the worm is continuously exposed to oxidizing molecules released by epithelial cells in the host ductal system and endogenous reactive oxygen species (ROS) generated by its own metabolic processes [7]. To ensure its long survival within the host bile ducts, the adult worm continuously releases bioactive molecules to cope with the cytopathic environments. The proteinaceous and nonproteinaceous components secreted by the parasites are referred to as excretory-secretory proteins (ESPs) [8]. The ESPs of C. sinensis (CsESPs) can cause histopathological changes, such as bile duct dilatation, inflammation and fibrosis as well as adenomatous proliferation of the biliary epithelium, which may be intimately associated with the formation of cholangitis, liver cirrhosis and cholangiocarcinoma (CCA).

Myoglobin (Mb), a hemoprotein, is present in high concentrations in trematodes and ESPs, and it may be implicated in host-parasite interactions. Most trematodes host cytoplasmic myoglobins, which are monomeric and approximately $17 \mathrm{kDa}$ in size. Thus far, monomeric myoglobin/hemoglobin from the Paramphistomum epiclitum (P. epiclitum) is the best characterized trematode $\mathrm{Mb}$, and it is monomeric and displays the major determinants of the typical globin fold [9-11]. The heme-ligand binding site displays a TyrB10/TyrE7 distal residue pair and a high oxygen affinity [12]. The crystal structure of P. epiclitum myoglobin shows that the heme distal site pocket residue, TyrB10, is engaged in hydrogen bonding to the ironbound ligand [13].

The physiological roles of trematode Mbs are a matter of debate. Indeed, adult parasitic trematodes and nematodes, such as Ascaris suum, live mainly in a semi-anaerobic environment, and their Mbs display such high oxygen affinities that they cannot simply serve in $\mathrm{O}_{2}$ transport to the tissues. Therefore, other functions for these Mbs, such as oxygen scavenging, heme reserve for egg production, and NO dioxygenase, have been proposed [14-16]. Additionally, Mbs share many physical, spectroscopic and chemical similarities with authentic peroxidases.
Thus, Mbs can act as a peroxidase and scavenge hydrogen peroxide $\left(\mathrm{H}_{2} \mathrm{O}_{2}\right)[17,18]$, thereby protecting against oxidative damage [19]. Moreover, it has been reported that Dehaloperoxidase (DHP; discovered in the terebellid polychaete, Amphitrite ornata) is the first heme-containing globin with peroxidase activity. DHP retains an oxygen carrier function but also has the ability to degrade halophenol toxicants in its living environment [20]. Accordingly, Mbs might contribute to the defense against soluble hydroperoxide in catalase-deficient trematode species.

Here, we describe the molecular characteristics and biological function of $\mathrm{CsMb}$ as well as its putative role in the interaction of C. sinensis with its host. We investigated the transcriptional levels of $C s \mathrm{Mb}$ in adult liver flukes under different culture conditions and observed the effects of recombinant $C s \mathrm{Mb}(\mathrm{rCs} \mathrm{Mb}$ ) on RAW264.7 cell modulation. Based on these results, we proposed that $\mathrm{Cs} \mathrm{Mb}$ functions as a component of the anti-oxidative survival strategy of $C$. sinensis in the host.

\section{Methods}

\section{Ethics statement}

All animals were housed in accordance with guidelines from the Association for the Assessment and Accreditation of Laboratory Animal Care (AAALAC). All protocols for animal infections were approved by the Institutional Review Board and conducted in the Institutional Animal Care and Use Committee (IACUC) of Sun Yat-sen University (permit number SCXK (Guangdong) 2009-2011).

\section{Preparation of parasites}

C. sinensis metacercariae were collected from naturally infected freshwater fish (Pseudorasbora parva) in an ecological pool using pepsin digestion as previously described [21]. Sprague-Dawley rats were infected with metacercariae by a gavage needle (100 metacercariae per rat). Worms were harvested from the bile ducts after 12 weeks. Viable intact worms were collected under a dissecting microscope. Eggs of $C$. sinensis were obtained as described previously [22]. The intact living adults of $C$. sinensis were placed in serum-free DMEM medium (Gibco, USA) at $37^{\circ} \mathrm{C}$ for $1 \mathrm{~h}$ to ensure emptying of the guts. The worms were then incubated in the absence or presence of oxygen (1, 5 and $20 \%$ ) at $37^{\circ} \mathrm{C}$ under $5 \% \mathrm{CO}_{2}$ for $24 \mathrm{~h}$ or $\mathrm{H}_{2} \mathrm{O}_{2}$ $(0-1.8 \mathrm{mM})$ at $37^{\circ} \mathrm{C}$ for $1 \mathrm{~h}$ (10 worms/group $/ 3 \mathrm{ml}$ of medium). Worms treated in DMEM medium at $37^{\circ} \mathrm{C}$ for $10 \mathrm{~min}$ were used as a negative control. Worms incubated at $37^{\circ} \mathrm{C}$ for $10 \mathrm{~min}$ in DMEM medium without $\mathrm{H}_{2} \mathrm{O}_{2}$ were included as negative controls. After incubation, the worms were washed three times with ice-chilled phosphatebuffered saline (PBS; pH 7.2) and were immediately used for the extraction of proteins and RNA. All procedures were repeated in triplicate. 


\section{Bioinformatics analysis of CsMb}

Homologous sequences were searched for using the Basic Local Alignment Search Tool X (BLASTx) program of the National Center for Biotechnology Information (NCBI), National Institutes of Health (Bethesda, Maryland). Sequence alignment with other previously reported Mbs (Sequence information shown in Additional file 1: Table S1) in the database was performed using the Clustal W (version 1.82) program of the European Bioinformatics Institute server (http://www.ebi.ac.uk/Tools/msa/clustalw2/). Signal peptides were predicted by SignalP (http://www.cbs. dtu.dk/services/SignalP/). Predicted motifs and secondary structures were obtained through PredictProtein (https:// www.predictprotein.org/) provided by the Columbia University Bioinformatics Center (New York, USA). The Conserved Domain Database of NCBI was used to identify the protein families and domains. The tertiary structures of $C s \mathrm{Mb}$ were simulated by the Discovery Studio 3.5 Client program and compared with P. epiclitum hemoglobin (Protein Data Bank id: 1KFR; 40\% identity). The PHYLIP 3.67 program package was used for phylogenetic tree reconstructions, and divergence rates were calculated using the Jukes-Cantor-Thornton mode. The statistical significance of branching nodes was predicted by observing their frequencies in 1000 bootstrap trees using the Seqboot program.

\section{Preparation of recombinant CsMb, antiserum of recombinant CsMb and CsESPs}

The expression and purification of recombinant $C s \mathrm{Mb}$ $(\mathrm{r} C s \mathrm{Mb})$ as well as the preparation of the antiserum of $\mathrm{rCsMb}$ and $C s$ ESPs are described in the additional file.

\section{Site-directed mutagenesis of $C$. sinensis myoglobin}

Site-directed mutants of Y34A and Y68A were generated using the QuickChange II site-directed mutagenesis kit (Agilent, USA) using the primers listed in Table 1. All mutations were confirmed with DNA sequencing performed by the Meiji Biotechnology Company (Shanghai, China). The mutant proteins were expressed and purified as described in the additional file.

\section{Immunohistochemical localization of CsMb in C. sinensis adults and metacercariae}

Fresh adult worms and metacercariae of $C$. sinensis were fixed with $4 \%$ formaldehyde, embedded with paraffin wax, and sliced into $4-\mu \mathrm{m}$ thick sections. After dewaxing and dehydration, the slides were blocked with goat serum overnight at $4^{\circ} \mathrm{C}$, and the slides were then incubated with rat anti-rCsMb sera (1:100 in $0.1 \%$ PBS-T) at room temperature for $2 \mathrm{~h}$. Serum from naïve rats was used as a negative control. The slides were washed twice and incubated with goat anti-rat IgG labeled with red fluorescent Cyanine dye 3 (Cy3, Proteintech; 1:400 in 0.1\%
Table 1 Primers used in this study

\begin{tabular}{|c|c|}
\hline Primer & Sequence $\left(5^{\prime} \rightarrow 3^{\prime}\right)$ \\
\hline \multicolumn{2}{|c|}{ Generation of recombinant CsMb protein } \\
\hline CsMb-F & AGAGGATCCATGGCACCCCTATCAA \\
\hline CsMb-R & CGTCTCGAGTTAGCCAAGAAAGCCG \\
\hline \multicolumn{2}{|c|}{ Preparation of mutant CsMb proteins } \\
\hline CsMb-Y34A-F & GAATTTGGAAAAGCAGTCGCCATGGCTCTGTTCTCAG \\
\hline CsMb-Y34A-R & CTGAGAACAGAGCCATGGCGACTGCTTITCCAAATTC \\
\hline CsMb-Y68A-F & GAGGGGATTAAGTACGCCGGCCAGACCTTTGC \\
\hline CsMb-Y68A-R & GCAAAGGTCTGGCCGGCGTACTTAATCCCCTC \\
\hline \multicolumn{2}{|c|}{ Detection of CsMb transcripts via RT-PCR } \\
\hline CsMb-RT-F & GCTGAACCCGTTGGTGAGTA \\
\hline CsMb-RT-R & TCACTGGTAGAGATGAAAGGGC \\
\hline $\operatorname{cs} \beta$-actin - RT-F & ACCGTGAGAAGATGACGCAGA \\
\hline Cs $\beta$-actin -RT-R & GCCAAGTCCAAACGAAGAATT \\
\hline \multicolumn{2}{|c|}{ Mouse specific primers } \\
\hline iNOS-F & GCAATATAGGCTCATCCAG \\
\hline iNOS-R & AACTCGCTCCAAGATTCC \\
\hline Sod1-F & ATTACAGGATTAACTGAAGG \\
\hline Sod1-R & CAATGATGGAATGCTCTC \\
\hline Sod2-F & ACAAACCTGAGCCCTAAG \\
\hline Sod2-R & CTCCCAGTTGATTACATTCC \\
\hline$\beta$-actin - $F$ & AACCGCGAGAAGATGACCCAGATCATGTTT \\
\hline$\beta$-actin $-R$ & AGCAGCCGTGGCCATCTCTTGCTCGAAGTC \\
\hline
\end{tabular}

PBS-T). Fluorescence microscopy (ZEISS Axio Imager Z1 fluorescent microscope, GER) was used to visualize the antibody staining.

\section{Peroxidase activity of $\mathrm{rCs} \mathrm{Mb}$ and mutants}

The peroxidase activities of wild-type and mutant C. sinensis myoglobins were measured at $20^{\circ} \mathrm{C}$ in $50 \mathrm{mM}$ sodium phosphate buffer ( $\mathrm{pH}$ 7.0). All experiments were performed in duplicate for each experimental point. The steady state kinetic constants for the oxidation of guaiacol and 2,2'-azinobis(3-ethylbenzothiazoline-6-sulfonic acid) (ABTS) were obtained by measuring the initial rates while varying the substrate concentration. A Hanes plot of $[\mathrm{S}] / v$ versus $[\mathrm{S}]$ was used to estimate the $\mathrm{V}_{\max }$ and $K_{m}$ values. The formation rate of the guaiacol oxidation product was determined from the increase in the absorbance at $470 \mathrm{~nm}$ using a molar extinction coefficient of $3.8 \times 10^{3} \mathrm{M}^{-1} \mathrm{~cm}^{-1}$. The $1-\mathrm{ml}$ final assay volume contained $1 \mu \mathrm{M} \mathrm{rCsMb}, 0.2 \mathrm{mM} \mathrm{H}_{2} \mathrm{O}_{2}$, and variable amounts of guaiacol $(0.08-2.5 \mathrm{mM})$. The formation of an ABTS cation radical was monitored at $730 \mathrm{~nm}$, where the absorption of $\mathrm{rCs} \mathrm{Mb}$ was negligible. The absorption coefficient of the ABTS cation radical at $730 \mathrm{~nm}\left(\varepsilon_{730}=1.4 \times 10^{4} \mathrm{M}^{-1} \mathrm{~cm}^{-1}\right)$ 


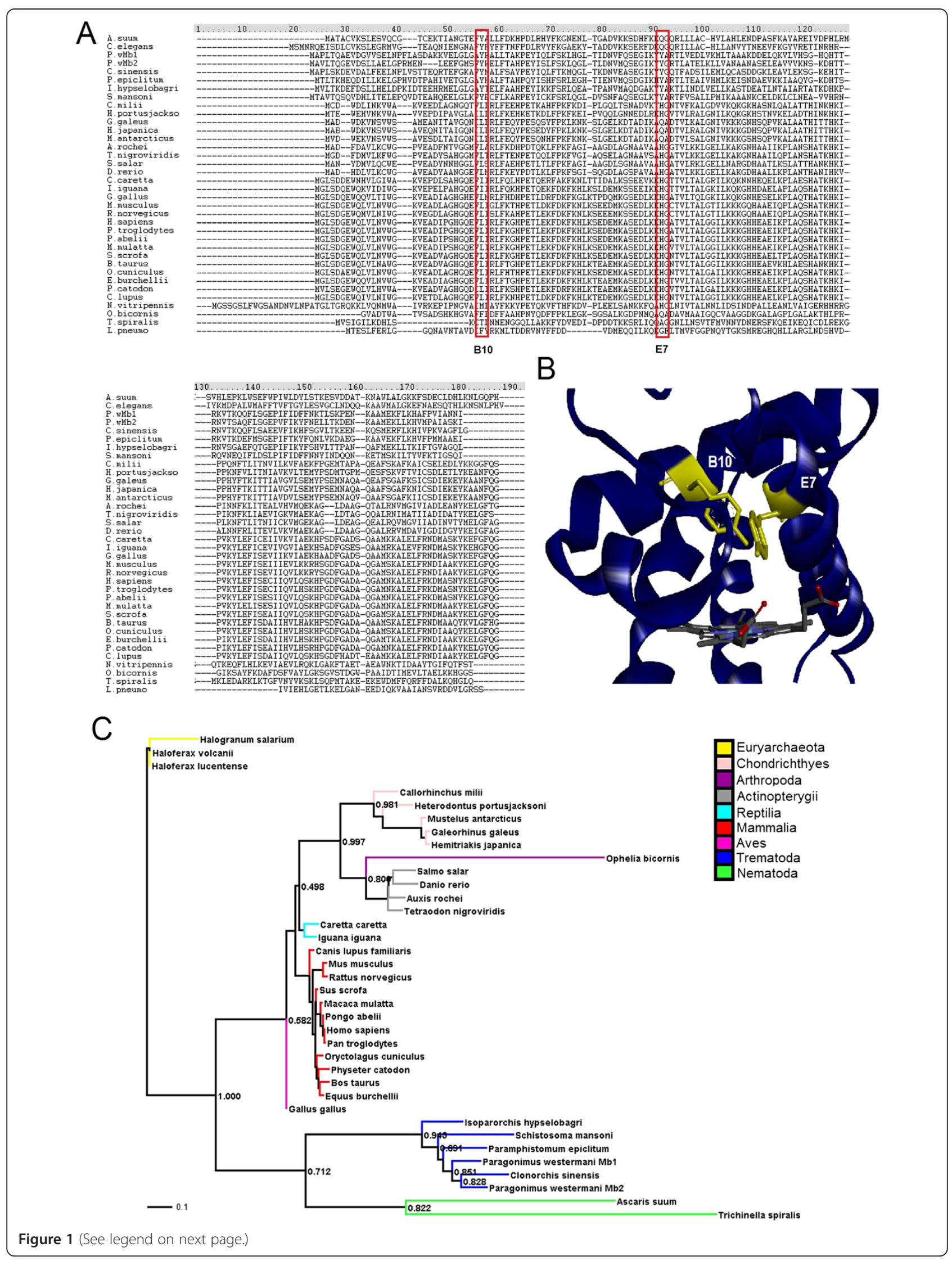


(See figure on previous page.)

Figure 1 Sequences and structure comparisons between Clonorchis sinensis myoglobin (CsMb) and its orthologues. (A) The amino acid sequence of CSMb was aligned with those of related proteins, which were retrieved from the GenBank database by BLAST searches (Sequence information shown in Additional file 1: Table S1). The red boxes indicate active tyrosine. (B) The tertiary structure of CsMb was simulated by the Discovery Studio 3.5 Client program and compared with P. epiclitum hemoglobin (Protein Data Bank id: 1KFR; 40\% identity). Regions around the active site are shown in yellow indicating the positions of critical amino acids (red boxes in panel $\mathbf{A}$ ). (C) Phylogenetic analysis. The majority-role consensus tree was derived from a neighbor-joining tree of the amino acid alignment, which was constructed by the PHYLIP program. The homologues from euryarchaeota were included in the root of the tree. Arabic numerals at branching nodes indicate their percentages of appearance in 1000 bootstrap replicates.

was calculated from that at $415 \mathrm{~nm}\left(3.6 \times 10^{4} \mathrm{M}^{-1} \mathrm{~cm}^{-1}\right)$. The reaction mixture contained $0.5 \mu \mathrm{M}$ rCs $\mathrm{Mb}, 0.2 \mathrm{mM}$ $\mathrm{H}_{2} \mathrm{O}_{2}$, and 20 -300 mM ABTS.

\section{Treatment of RAW264.7 cells}

RAW 264.7 macrophages were purchased from American Type Culture Collection (ATCC). RAW 264.7 cells were maintained in DMEM supplemented with $10 \%(\mathrm{v} / \mathrm{v})$ fetal bovine serum (FBS), $100 \mathrm{U} / \mathrm{ml}$ penicillin and $100 \mu \mathrm{g} / \mathrm{ml}$ streptomycin at $37^{\circ} \mathrm{C}\left(5 \% \mathrm{CO}_{2}\right)$. Exponentially growing RAW264.7 cells were digested with $2.5 \mathrm{mg} / \mathrm{ml}$ trypsin and suspended in DMEM to a concentration of $2 \times 10^{5}$ cells $/ \mathrm{ml}$. Subsequently, the cells were plated in 6 -well flat-bottomed microculture plates $(2 \mathrm{ml} /$ well $)$ and cultured at $37^{\circ} \mathrm{C}$ in a $5 \% \mathrm{CO}_{2}$ atmosphere for $2 \mathrm{~h}$. The cultures were washed to remove non-adherent cells and then incubated with $2 \mathrm{ml}$ of DMEM supplemented with 10\% (v/v) fetal bovine serum, $100 \mathrm{U} / \mathrm{ml}$ penicillin and $100 \mu \mathrm{g} / \mathrm{ml}$ streptomycin for an additional $20 \mathrm{~h}$.

For the experiments, the following three groups of cells were used: control group, cells were activated with only PBS; LPS group, cells were activated with LPS and PBS; and rCsMb group, cells were activated with LPS and $\mathrm{rCsMb}$. The culture medium of all groups was replaced with FBS-free DMEM for 30 min to allow cells to adjust. LPS $(100 \mathrm{ng} / \mathrm{ml})$ was then added to all groups, except the control group, to activate the macrophages. Purified $\mathrm{rCsMb}$ was added to each group at a final concentration of $5 \mu \mathrm{g} / \mathrm{ml}$. Cells were further incubated for the desired experimental periods.

\section{Determination of $\mathrm{NO}$ and $\mathrm{H}_{2} \mathrm{O}_{2}$}

The level of $\mathrm{NO}$ and $\mathrm{H}_{2} \mathrm{O}_{2}$ was analyzed by a Nitric Oxide Assay Kit and Hydrogen Peroxide Assay Kit (Beyotime Institute of Biotechnology, China). The absorbance was measured at $540 \mathrm{~nm}$ using a microplate reader (Biorad Benchmark, USA).

\section{RNA extraction and complementary DNA (cDNA) synthesis}

Total RNA from adult worms, excysted metacercariae, metacercariae, and eggs was extracted in Trizol reagent (Invitrogen) according to the protocol recommended by the manufacturer. RNA concentration and quality were detected by a nucleic acid/protein analyzer (Beckman Coulter, USA) and agarose gel electrophoresis, respectively. For reverse transcription, the reaction was performed in a final volume of $20 \mu \mathrm{l}$ containing $2 \mu \mathrm{g}$ of total RNA, $2.5 \mu \mathrm{M}$ oligo dT primer, and five units of avian myeloblastosis virus (AMV) reverse transcriptase (TaKaRa, Japan). The reaction mixture was then incubated for $1 \mathrm{~h}$ at $42^{\circ} \mathrm{C}$ and heated for $5 \mathrm{~min}$ at $95^{\circ} \mathrm{C}$.

\section{Real-time quantitative reverse transcription-PCR (real-time qRT-PCR)}

To analyze the mRNA transcription levels of CsMb at different developmental stages of C. sinensis, PCR was performed using the cDNA templates from different developmental stages of $\mathrm{C}$. sinensis, which contained $10 \mu \mathrm{l}$ of $2 \times$ SYBR Premix Ex Taq (TaKaRa, Japan), $2 \mu$ of diluted cDNA template, $7.2 \mu$ l of PCR-grade water, and $0.4 \mu \mathrm{l}$ of each $10 \mu \mathrm{M}$ primer. The PCR conditions were as follows: $95^{\circ} \mathrm{C}$ for $30 \mathrm{~s}$ followed by 40 cycles of $95^{\circ} \mathrm{C}$ for $5 \mathrm{~s}$ and $60^{\circ} \mathrm{C}$ for $20 \mathrm{~s}$ with a $0.1^{\circ} \mathrm{C} / \mathrm{s}$ incremental increase from 60 to $95^{\circ} \mathrm{C}$. Cs Mb primers were specifically designed by Premier 5.0, we did test all primers specific efficiency by Primer-BLAST. C. sinensis $\beta$-actin (GenBank accession number EU109284) was used as an internal control. All primers used in this study are listed in Table 1 . The relative quantification analysis was performed by calculating the values of $2^{-\Delta \Delta C T}$. All experiments were performed in duplicate for each experimental point.

\section{Statistical analysis}

All experiments were repeated at least three times, and the data were analyzed by one-way analysis of variance (ANOVA) and the Students-Newmann-Keuls (SNK) test using the SPSS software package 17.0. Experimental values were obtained from three independent experiments with a similar pattern and expressed as the means \pm standard deviation (SD). P-values less than 0.05 were considered significant.

\section{Results}

\section{Bioinformatics analysis}

The CsMb gene was identified from the C. sinensis genome [23]. Analysis of the presence of a secretory signal peptide indicated that $C s \mathrm{Mb}$ had no signal peptide 

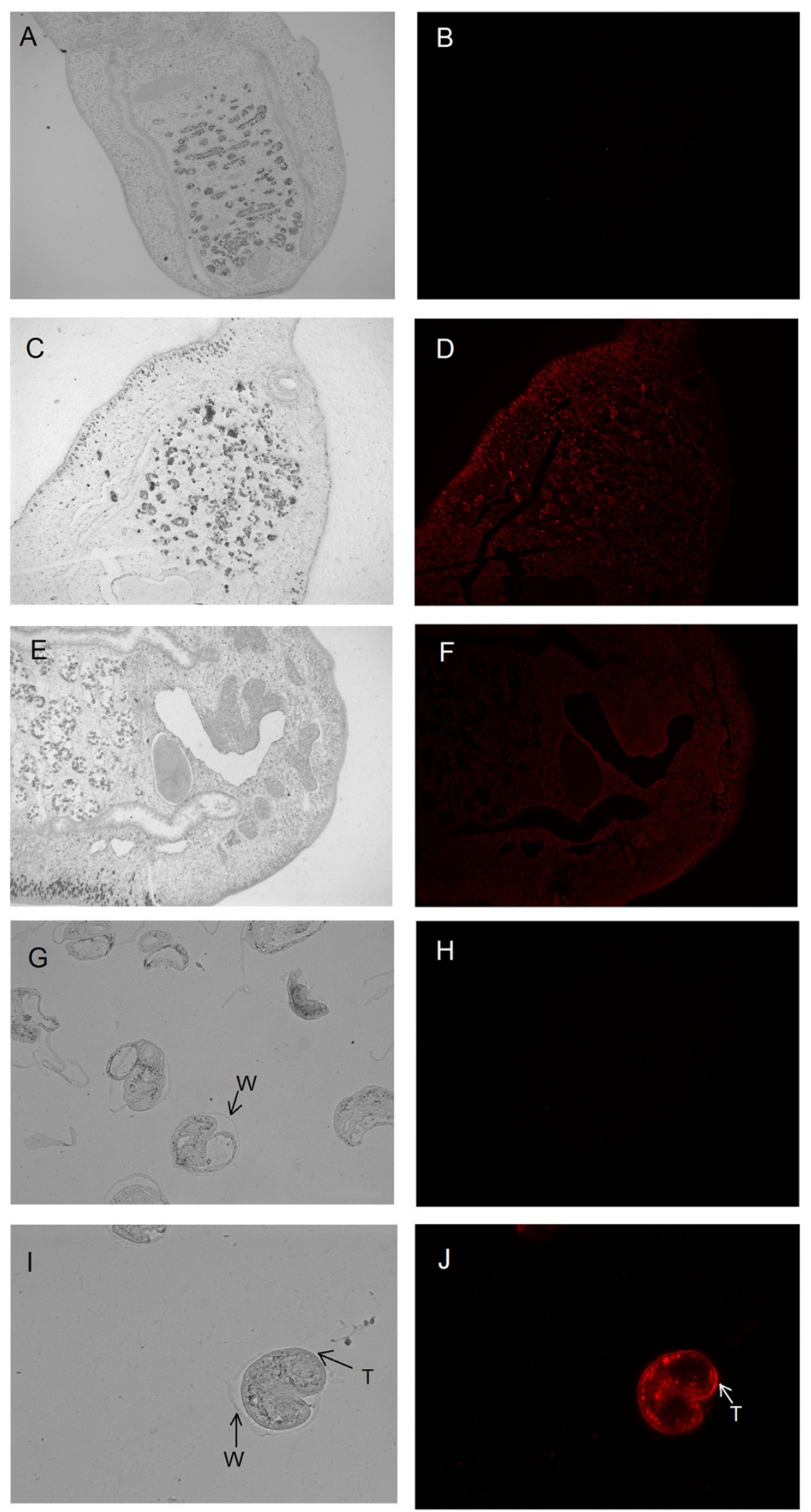

Figure 2 (See legend on next page.) 
(See figure on previous page.)

Figure $\mathbf{2}$ Immunolocalization of CsMb in adult worm and metacercaria of $\boldsymbol{C}$. sinensis. Rat anti-rCsMb serum was used as the primary antibody and red fluorescent Cy3-labeled goat anti-rat lgG as the secondary antibody. Slides were observed under white light (panel $\mathbf{A}$, $\mathbf{C}$, $\mathbf{E}$, G, and I) or under a fluorescence microscope (panel $\mathbf{B}, \mathbf{D}, \mathbf{F}, \mathbf{H}$, and $\mathbf{J}$ ). No specific fluorescence was observed in panel $\mathbf{B}$ or $\mathbf{H}$, which was probed with serum from rats immunized with PBS as a negative control. Intensive reddish-orange fluorescent signals were observed in the subtegumental and mesenchymal tissues of the adult worm (panel $\mathbf{D}$ and $\mathbf{F} ; \times 50$ ) as well as the vitellarium of the metacercaria (panel $\mathbf{J} ; \times 200$ ). Scattered fluorescent signals were detected in the tegument of the metacercaria. T, tegument. W, cyst wall.

sequence and that it had a value higher than the threshold value $(0.5)$ for the possibility of non-classical secretion. Sequence alignment revealed that CsMb contained the characteristic tyrosyl residue substitution at the helical positions of B10 and E7 (distal) of trematode Mbs (Figure 1A), which distinguished the Mbs of trematode from other organisms. PredictProtein indicated the presence of 8 helices in $C s \mathrm{Mb}$, which are fundamental to $\mathrm{Mb}$ proteins. The comparison around the active site is shown in Figure 1B.

\section{Phylogenetic position of CsMb}

Based on the BLAST search results, $\mathrm{Mb}$ amino acid sequences of 37 species were selected to examine the phylogenetic position of $C s \mathrm{Mb}$. The neighbor-joining method in PHYLIP clearly separated these proteins into distinct clades according to the taxonomical positions of the donors, such as euryarchaeota, nematoda, trematoda, chordata and mammalia (a major rule tree is presented in Figure $1 \mathrm{C}$ ). The phylogenetic tree indicated that $\mathrm{Cs} \mathrm{Mb}$ had high homology to trematode Mbs. Among the trematoda, the two Mbs of $P$. westermani were related to $C s \mathrm{Mb}$. As expected, Mbs from vertebrates and trematoda formed their respective groups. Sperm whale $\mathrm{Mb}$, an extensively studied and well-characterized $\mathrm{Mb}$, was included as a typical representative of mammalian Mbs that are clearly different from trematoda Mbs in the primary structure. Euryarchaeota Mbs were used to root the tree.

\section{Immunolocalization of $\mathrm{CsMb}$ in the adult worm and metacercaria of $C$. sinensis}

The analysis of immunofluorescence localization in $C$. sinensis adults using rat anti-rCsMb serum showed intense intracellular fluorescence in the subtegumental and mesenchymal tissues. In the metacercaria, the fluorescence was localized in the tegument and vitellarium (Figure 2D, F and J). By comparison, no specific fluorescence was detected in either the adult worm or metacercaria when treated with serum from naïve rats (Figure $2 \mathrm{~B}$ and $\mathrm{H}$ ).

\section{Transcriptional levels of $\mathrm{Mb}$ in $\mathrm{C}$. sinensis incubated in different conditions}

CsMb mRNA levels were detected by real time-PCR when the parasites were cultured in three different conditions. Interestingly, the transcription level of $C s \mathrm{Mb}$ in $20 \%$ oxygen was the highest, and the transcription level of $\mathrm{CsMb}$ in $1 \%$ oxygen was the lowest (Figure $3 \mathrm{~A}$ ). We assessed the induction profile of $\mathrm{Cs} \mathrm{Mb}$ upon stimulation with oxidative chemicals $\left(\mathrm{H}_{2} \mathrm{O}_{2}\right)$. The worms were stimulated with $\mathrm{H}_{2} \mathrm{O}_{2}(0-1.8 \mathrm{mM})$ at $37^{\circ} \mathrm{C}$ for $1 \mathrm{~h}$. Oxidative stress conditions created by $\mathrm{H}_{2} \mathrm{O}_{2}$ increased the mRNA level of $C s \mathrm{Mb}$ in a dose-dependent manner (Figure $3 \mathrm{~B}$ ).
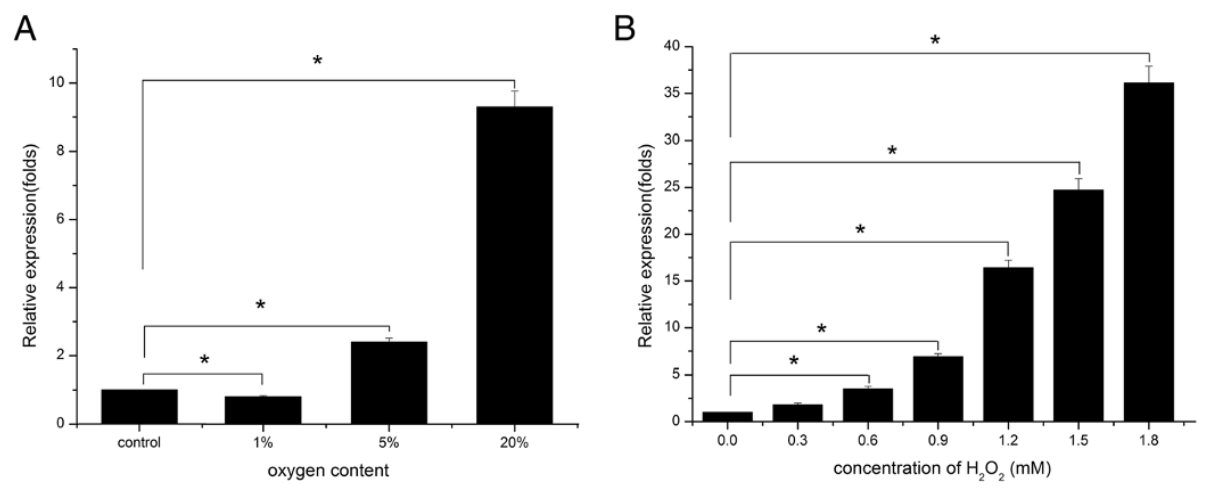

Figure $\mathbf{3}$ Transcriptional level of $\mathbf{M b}$ in $\mathbf{C}$. sinensis incubated in different oxygen contents. (A) The fold increase was calculated by comparing intensities between experimental and control groups. The CsMb transcripts were much higher in the $20 \%$ oxygen group than in the $1 \%$ oxygen group. The transcriptional level of CsMb in the 5\% oxygen group was 3-fold higher than that in the $1 \%$ oxygen group. (B) Changes of $\mathrm{Mb}$ transcript levels in $\mathrm{C}$. sinensis caused by oxidative chemicals. The worms were stimulated with $\mathrm{H}_{2} \mathrm{O}_{2}(0-1.8 \mathrm{mM})$ for $1 \mathrm{~h}$ at $37^{\circ} \mathrm{C}$. $\mathrm{CsMb}$ transcript amounts were significantly increased at $\mathrm{H}_{2} \mathrm{O}_{2}$ concentrations greater than $0.6 \mathrm{mM}$. $\left.{ }^{*} p<0.01\right)$. 
There was no corresponding change at the transcription level of $\beta$-actin, so we know the response is specific.

\section{Peroxidase activity of $\mathrm{rCs} \mathrm{Mb}$ and mutants}

The residues at sites 34 and 68 of the $\mathrm{rCsMb}$ mutants are described in Additional file 1: Table S2. The $\mathrm{V}_{\max }$ and $K_{m}$ values for the peroxidase activity are summarized in Table 2. Wild-type $C s \mathrm{Mb}$ exhibited $\mathrm{V}_{\max }$ values 6-fold higher than those of the Y68A mutant both in the guaiacol and ABTS oxidation assays, and no significant activities for the Y34A and Y34A/Y68A mutants were observed. From the CsMb mutant reactions, we found that the tyrosyl at residue 34 played a critical role to activate $\mathrm{H}_{2} \mathrm{O}_{2}$. As shown in Table 2, removal of Tyr34 (Y34A mutants) showed no reactivity. To better illustrate the dual tyrosines at positions 34 and 68 accelerating the peroxidase activity, we plotted the time course for the reactions of different $\mathrm{rCs} \mathrm{Mbs}$ mutants with $\mathrm{H}_{2} \mathrm{O}_{2}$ according to the changes of absorbance at $407 \mathrm{~nm}$. The kinetic trace obeyed pseudo first-order kinetics in the incubation with $25 \mathrm{mM} \mathrm{H}_{2} \mathrm{O}_{2}$ (Figure 4).

\section{Production of $\mathrm{H}_{2} \mathrm{O}_{2}$ and NO in activated RAW264.7 cells}

Respiratory burst activity of macrophages in terms of $\mathrm{H}_{2} \mathrm{O}_{2}$ and NO levels were measured after $2 \mathrm{~h}$ and $24 \mathrm{~h}$, respectively. The $\mathrm{rCsMb}$-treated (LPS $+\mathrm{rCsMb}$ ) cells showed lower levels of $\mathrm{NO}$ and $\mathrm{H}_{2} \mathrm{O}_{2}(\mathrm{P}<0.05$, Figure 5) when compared to the LPS-activated (LPS + PBS) cells.

\section{Quantitation of mRNA levels of inducible nitric oxide} synthase (iNOS), Cu-Zn superoxide dismutase (SOD1) and Mn superoxide dismutase (SOD2)

After a $24 \mathrm{~h}$ incubation in the respective experimental conditions, the mRNA levels of iNOS, SOD1 and SOD2 were measured (Figure 6). Compared to the LPS + PBS or LPS $+\mathrm{rCsMb}$ cells, the mRNA levels of iNOS, SOD1 and SOD2 were significantly decreased in $\mathrm{r} C s \mathrm{Mb}$-treated cells.

Table 2 Rate constants of reactions between different mutants and $\mathrm{H}_{2} \mathrm{O}_{2}$

\begin{tabular}{lccccc}
\hline CsMb & \multicolumn{2}{c}{ Guaiacol } & & \multicolumn{2}{c}{ ABTS } \\
\cline { 2 - 3 } \cline { 5 - 6 } & $\mathbf{V}_{\mathbf{m a x}}$ & $\mathbf{K}_{\mathbf{m}}$ & & $\mathbf{V}_{\mathbf{m a x}}$ & $\mathbf{K}_{\mathbf{m}}$ \\
\hline Wild-type & 46 & 81 & 167 & 66 \\
Y34A & N.D. & N.D. & & N.D. ${ }^{*}$ & N.D. $^{*}$ \\
Y68A & 7.1 & 590 & 32 & 83 \\
Y34A/Y68A & N.D. & N.D. ${ }^{*}$ & N.D. & N.D. \\
\hline
\end{tabular}

Reactions were performed with $\mathrm{H}_{2} \mathrm{O}_{2}(\sim 20 \mu \mathrm{M})$ and oxygenated $\mathrm{rCsMb}$ solutions at $20^{\circ} \mathrm{C}$ and $\mathrm{pH}$ 7.0. The units are as follows: $\mathrm{V}_{\text {max }}, \mathrm{nmol}$ of product $/ \mathrm{nmol}$ of $\mathrm{rCsMb} / \mathrm{min}$; and $\mathrm{K}_{\mathrm{m}}, \mathrm{mM}$.

${ }^{*}$ Reaction rates were too slow to measure.

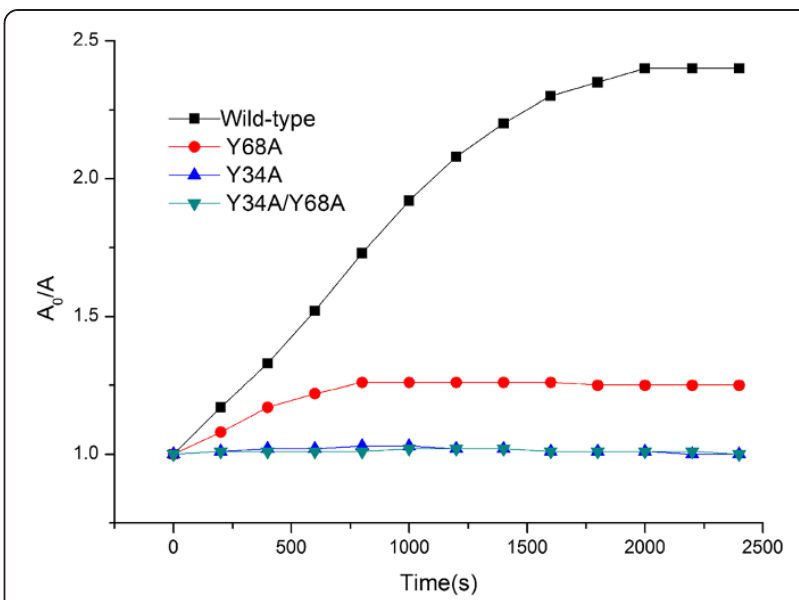

Figure 4 Peroxidase activity of $\mathrm{rCsMb}$ and mutants evaluated by spectrophotometry. Reactions were performed with $\mathrm{H}_{2} \mathrm{O}_{2}$ $(20 \mu \mathrm{M})$ and oxygenated $\mathrm{rCsMb}$ solutions at $20^{\circ} \mathrm{C}$ and $\mathrm{pH}$ 7.0. The $\mathrm{A}_{0} / \mathrm{A}$ ratio is the initial absorbance and final absorbance at $407 \mathrm{~nm}$. All mutants containing Y34A did not show $\mathrm{H}_{2} \mathrm{O}_{2}$ reactivity, and only Y68A exhibited lower reactivity than that of wild-type CsMb.

\section{Discussion}

The aim of this study was to evaluate the phylogenetic positions and functional characterization of $C s \mathrm{Mb}$ as well as to address its role in the pathogenesis of Clonorchiasis. The expression of $C s \mathrm{Mb}$ was highly inducible in response to exogenously introduced $\mathrm{H}_{2} \mathrm{O}_{2}$. Our results showed that $C s \mathrm{Mb}$ has peroxidase activity and may be important in the detoxification against $\mathrm{H}_{2} \mathrm{O}_{2}$ and other ROS.

It is widely accepted that Mbs serve as oxygen stores rather than oxygen transporters or as oxygen sensors in some cases, and they are found in bacteria, plants, protozoans and invertebrate nerve systems. Bioinformatics analysis showed that $C s \mathrm{Mb}$ comprised a globin family profile domain and heme-binding site. Although there was low amino acid sequence homology between the distantly related globins and the amino acid identity between human and $C$. sinensis myoglobins was only approximately $29 \%$, the Mbs were found to have a similar three-dimensional structure (the so-called myoglobin fold) (Figure 1). Our phylogenetic analysis showed that the vertebrate groups of Mbs were more closely related to each other and that the invertebrate globins were more divergent. As reported elsewhere, nonvertebrate globins show higher variability in their primary and tertiary structures, which might reflect their adaptations to specific functions compared with their vertebrate homologs [24]. trMbs are the most primitive animal globins [25] as indicated by the phylogenetic analysis of their primary structure. Because trMbs have such a high oxygen affinity and low rate of dioxygen dissociation, it seems unlikely that the function of trMbs is oxygen delivery. 

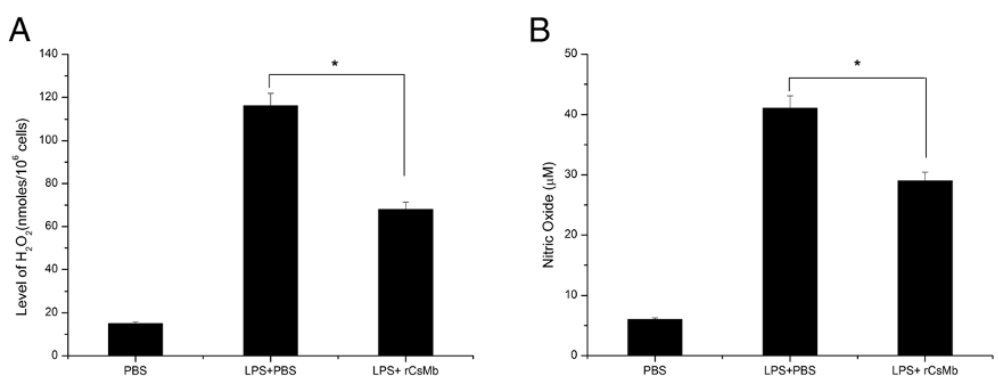

Figure 5 Production of $\mathrm{H}_{2} \mathrm{O}_{2}$ and $\mathrm{NO}$ in activated RAW264.7 cells in various conditions. In the respective experimental conditions, the $\mathrm{H}_{2} \mathrm{O}_{2}$ level was measured after $2 \mathrm{~h}$ (panel A), and the NO level was measured after $24 \mathrm{~h}$ (panel B). LPS $(100 \mathrm{ng} / \mathrm{ml})$ was used as a positive control. The levels of $\mathrm{H}_{2} \mathrm{O}_{2}$ and $\mathrm{NO}$ were significantly decreased in $\mathrm{rCsMb}$-treated cells compared to the levels of cells treated with LPS + PBS. ${ }^{*}$ indicates $p<0.01$.

Our study showed that $C s \mathrm{Mb}$ was transcribed in four developmental stages of $C$. sinensis, including adult worms, metacercariae, excysted metacercariae and eggs (Additional file 1: Figure S1). Quantitative real-time PCR analysis revealed that the transcription level of $\mathrm{Cs} \mathrm{Mb}$ mRNA was much higher in the adult stage than in the other stages, which may have been due to $C s \mathrm{Mb}$ playing an important role in long-term survival of the adult worms. Moreover, immunolocalization results showed that $C s \mathrm{Mb}$ was extensively distributed intracellularly in the subtegumental and mesenchymal tissues of adult worms, and these results also showed that $\mathrm{CsMb}$ was localized in the teguments of metacercariae (Figure 2). A previous study on the expressed sequence tag analysis of C. sinensis adults discovered that CsMb is one of the most abundant proteins in adult worms [26]. Moreover, $\mathrm{rCsMb}$ can be probed by $C$. sinensis-infected rat sera and ESP-immunized rat sera. ESPs can be probed with rat anti-rCsMb sera, resulting in a single band with a MW of approximately $17 \mathrm{kDa}$. In the present study,

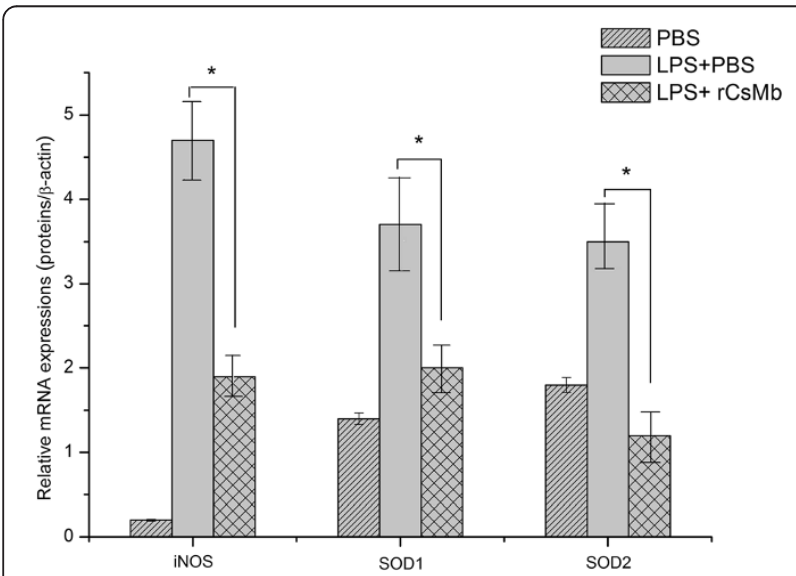

Figure 6 mRNA levels of various genes involved in the oxidative burst in RAW264.7 cells. The relative mRNA level is represented by the ratio of mRNAs to $\beta$-actin. The mRNA levels were significantly downregulated in cells treated with $\mathrm{rCs} M b$ compared the levels of cells treated with LPS + PBS. $\left({ }^{*} p<0.01\right)$. western blotting analysis confirmed that $C s \mathrm{Mb}$ was a molecular component of CsESPs (Additional file 1: Figure S2). As a food-borne parasite, C. Sinensis adult worms live in the bile ducts of the host, and the worm releases ESPs. Thus, $C s \mathrm{Mb}$ exists in sustained parasitism circumstances and participates in the interaction between the host and parasite.

We also cultured the adult worms in different concentrations of oxygen. The expression of $\mathrm{CsMb}$ gene was analyzed by qRT-PCR, which showed that $C s \mathrm{Mb}$ expression was upregulated after $24 \mathrm{~h}$. The 5 and $20 \%$ oxygen groups showed 2.1- and 5.4-fold increases, respectively, compared to the control group. In contrast, $C s \mathrm{Mb}$ gene expression in the $1 \%$ oxygen group was lower than that of the control group. These results demonstrated that $C s \mathrm{Mb}$ may be involved in aerobic metabolism and in the oxygen reservoir of adult worms. Moreover, these results showed that the existence of exogenous $\mathrm{H}_{2} \mathrm{O}_{2}$ significantly increased $C s \mathrm{Mb}$ transcripts of adult worms in a dose-dependent manner. Therefore, the expression of $C s \mathrm{Mb}$ was highly inducible in response to exogenously introduced $\mathrm{H}_{2} \mathrm{O}_{2}$, and $C s \mathrm{Mb}$ may exert its important role in response to exogenous stimulus.

Based on the transcriptional levels of CsMb under different culture conditions, we inferred that $C s \mathrm{Mb}$ may have peroxidase activity in addition to its role in the transportation and storage of oxygen. An analysis of the amino acid sequences also showed that $\mathrm{CsMb}$ contained a TyrB10/TyrE7 distal residue pair, which is a characteristic sequence signature of trematode globins. Tyrosine is present at the $\mathrm{B} 10$ and $\mathrm{E} 7$ positions in trematoda instead of the more common Leu (B10) and His (E7) positions in other species. The E7 and B10 positions are key amino acids of the heme pocket. In this work, we found that $C s \mathrm{Mb}$ had a specific peroxidase activity and that the tyrosine at residue 34 played a critical role in the reaction with $\mathrm{H}_{2} \mathrm{O}_{2}$. Replacing Tyr34 with Ala in CsMb resulted in no reaction to $\mathrm{H}_{2} \mathrm{O}_{2}$. Our finding suggested that $C s \mathrm{Mb}$ is of great importance in the detoxification of $\mathrm{H}_{2} \mathrm{O}_{2}$ and other ROS. A significant $\mathrm{H}_{2} \mathrm{O}_{2}$ interaction 
with $C s \mathrm{Mb}$ may question the viewpoint that a series of antioxidant enzymes, such as GSH S-transferase [27], Cys peroxiredoxins [28] and GSH peroxidase [29], participate in the removal of these detrimental oxidants. These enzymes are mainly responsible for dismutation of host oxidative stress to protect parasitic proteins, DNA and lipids from oxidative damage. Although these antioxidant enzymes have a higher affinity for $\mathrm{H}_{2} \mathrm{O}_{2}$ than Cs $\mathrm{Mb}, \mathrm{Cs} \mathrm{Mb}$ exists extensively and abundantly. Because decreased $\mathrm{H}_{2} \mathrm{O}_{2}$ levels eventually increase parasite survival and growth [30], CsMb may be an essential component of the main enzymatic scavenger for ROS in $C$. sinensis.

This study also showed that $\mathrm{rCsMb}$ decreased redox activation in a human macrophage cell line. In C. sinensis infection, reactive oxygen and nitrogen species play crucial roles in the initial events of parasite killing and elimination from the host [31]. To establish infection and ensure survival, $C$. sinensis has developed sophisticated strategies to evade the host immune responses. Despite a wealth of gained crucial information, these strategies still remain poorly understood. LPS is a potent activator of macrophage responses leading to the induction of various inflammatory mediators, such as reactive oxygen species, nitrogen species and inflammatory cytokines. We treated LPS-stimulated RAW264.7 cells with $\mathrm{rCsMb}$, and we found that $\mathrm{rCsMb}$ effectively reduced $\mathrm{H}_{2} \mathrm{O}_{2}$ and $\mathrm{NO}$ levels in LPS-activated cells as well as the expression levels of iNOS and SODs. Because decreased $\mathrm{H}_{2} \mathrm{O}_{2}$ levels eventually augment parasite survival, it is likely that $C$. sinensis silences macrophages by secreting $C s \mathrm{Mb}$ to suppress host immune responses. The results clearly showed that $C s \mathrm{Mb}$ may have immunomodulatory functions.

The purpose of a host oxidative assault is to eliminate parasitic invasion, and it is also a critical link for various inflammatory responses of the host [32]. Parasites can regulate the host immune responses to maintain the parasitism for a prolonged period, but the molecules governing this process are not yet identified. Parasitic products interfere with lymphocytes and their products, such as antibodies, resulting in a modified immune response. Ancylostoma caninum produces factors, such as neutrophil inhibitory factor (NIF), capable of inhibiting the neutrophil-endothelium adhesion [33]. Our present study indicated that $C s \mathrm{Mb}$ in adult worms not only acts to store oxygen but can also counter oxidative assaults. CsMb may take part in the anti-oxidative survival strategy of $C$. sinensis in the host.

\section{Conclusion}

In conclusion, our data demonstrated that in vitro culture of adult worms with exogenous $\mathrm{H}_{2} \mathrm{O}_{2}$ increases the level of $\mathrm{CsMb}$ transcripts. The increased $\mathrm{Cs} \mathrm{Mb}$ expression may potentially act as an antioxidant enzyme and may be involved in the host immune response. Thus, the reduced expression levels of iNOS and SODs as well as the low levels of $\mathrm{NO}$ and $\mathrm{H}_{2} \mathrm{O}_{2}$ in rCsMb-treated RAW264.7 cells may contribute to the control of the redox activation of macrophages during $C$. sinensis infection. The peroxidase activity of $C s \mathrm{Mb}$ and decrease of redox activation in human macrophages may contribute to the establishment and maintenance of the anti-oxidative survival strategy of $C$. sinensis in the host. A detailed study is required to fully understand the role of CsMb in the pathogenesis of $C$. sinensis for effective control of Clonorchiasis worldwide.

\section{Additional file}

Additional file 1: Figure S1. Quantitative real-time PCR analysis of CsMb at different life cycle stages of C. sinensis. Figure S2. Determination of $\mathbf{C s M b}$ as a component of $\boldsymbol{C}$. Sinensis ESPs. Table $\mathbf{S} 1$. Sequences information of homologues from other species Table S2. Residues at site 34 and 68 of wild-type CsMb and different mutants.

\section{Competing interests}

The authors declare that we have no competing interests.

\section{Authors' contributions}

MYR, LH, YH, XYW and XBY conceived and designed the experiments; MYR, LH, MB, QM, SL, HLQ, PL, JSL, TJC, CL performed the experiments; MYR, LH analyzed the data; MYR, LH, XRL and YH wrote the manuscript; All authors read and approved the final manuscript.

\section{Acknowledgments}

This work was supported by the National Key Basic Research and Development Project of China (973 project; No.2010CB530000), National Natural Science Foundation of China (No.81101270 and No. 81171602), the National S \& T Major Program (2012ZX10004-220), Fundamental Research Funds for the Central Universities of China (No. 3164015), and Guangdong Natural Science Foundation (No. S2012010008504).

\section{Author details}

${ }^{1}$ Department of Parasitology, Zhongshan School of Medicine, Sun Yat-sen University, 74 Zhongshan 2nd Road, Guangzhou, Guangdong 510080, China. ${ }^{2}$ Key Laboratory for Tropical Diseases Control (Sun Yat-sen University), Ministry of Education, 74 Zhongshan 2nd Road, Guangzhou, Guangdong 510080, China. ${ }^{3}$ Department of Pathogen Biology, Hainan Medical College, Haikou, Hainan 571199, China.

Received: 22 February 2014 Accepted: 22 May 2014

Published: 29 May 2014

\section{References}

1. Lun ZR, Gasser RB, Lai DH, Li AX, Zhu XQ, Yu XB, Fang YY: Clonorchiasis: a key foodborne zoonosis in China. Lancet Infect Dis 2005, 5:31-41.

2. Lin RQ, Tang JD, Zhou DH, Song HQ, Huang SY, Chen JX, Chen MX, Zhang $H$ Zhu XQ, Zhou XN: Prevalence of Clonorchis sinensis infection in dogs and cats in subtropical southern China. Parasit Vectors 2011, 4:180.

3. Xu Y, Chen W, Bian M, Wang X, Sun J, Sun H, Jia F, Liang C, Li X, Zhou X, Huang $Y, Y U X$ : Molecular characterization and immune modulation properties of Clonorchis sinensis-derived RNASET2. Parasit Vectors 2013, 6:360.

4. Chen J, Xu MJ, Zhou DH, Song HQ, Wang CR, Zhu XQ: Canine and feline parasitic zoonoses in China. Parasit Vectors 2012, 5:152.

5. Fried B, Abruzzi A: Food-borne trematode infections of humans in the United States of America. Parasitol Res 2010, 106:1263-1280. 
6. Attwood HD, Chou ST: The longevity of Clonorchis sinensis. Pathology 1978, 10:153-156.

7. Kumagai T, Osada Y, Kanazawa T: 2-Cys peroxiredoxins from Schistosoma japonicum: the expression profile and localization in the life cycle. $\mathrm{Mol}$ Biochem Parasitol 2006, 149:135-143.

8. Pak JH, Moon JH, Hwang SJ, Cho SH, Seo SB, Kim TS: Proteomic analysis of differentially expressed proteins in human cholangiocarcinoma cells treated with Clonorchis sinensis excretory-secretory products. J Cell Biochem 2009, 108:1376-1388.

9. Pomaznoy M, Tatkov S, Katokhin A, Afonnikov D, Babenko V, Furman D, Brusentsov I, Belavin P, Najakshin A, Guselnikov S, Vasiliev G, Sivkov A, Prokhortchouk E, Skryabin K, Mordvinov V: Adult Opisthorchis felineus major protein fractions deduced from transcripts: Comparison with live flukes Opisthorchis viverrini and Clonorchis sinensis. Exp Parasitol 2013, 135:297-306.

10. Das TK, Dewilde S, Friedman JM, Moens L, Rousseau DL: Multiple active site conformers in the carbon monoxide complexes of trematode hemoglobins. J Biol Chem 2006, 281:11471-11479.

11. Kiger L, Rashid AK, Griffon N, Haque M, Moens L, Gibson QH, Poyart C Marden MC: Trematode hemoglobins show exceptionally high oxygen affinity. Biophys J 1998, 75:990-998.

12. Dewilde S, loanitescu Al, Kiger L, Gilany K, Marden MC, Van Doorslaer S, Vercruysse J, Pesce A, Nardini M, Bolognesi M, Moens L: The hemoglobins of the trematodes Fasciola hepatica and Paramphistomum epiclitum: a molecular biological, physico-chemical, kinetic, and vaccination study. Protein Sci 2008, 17:1653-1662.

13. Pesce A, Dewilde S, Kiger L, Milani M, Ascenzi P, Marden MC, Van Hauwaert $M L$, Vanfleteren J, Moens L, Bolognesi M: Very high resolution structure of a trematode hemoglobin displaying a TyrB10-TyrE7 heme distal residue pair and high oxygen affinity. J Mol Biol 2001, 309:1153-1164.

14. de Guzman JV, Yu HS, Jeong HJ, Hong YC, Kim J, Kong HH, Chung DI: Molecular characterization of two myoglobins of Paragonimus westermani. J Parasitol 2007, 93:97-103.

15. Goldberg DE: The enigmatic oxygen-avid hemoglobin of Ascaris. Bioessays 1995, 17:177-182.

16. Rashid AK, Weber RE: Functional differentiation in trematode hemoglobin isoforms. Eur J Biochem 1999, 260:717-725.

17. Helbo S, Dewilde S, Williams DR, Berghmans H, Berenbrink M, Cossins AR, Fago A: Functional differentiation of myoglobin isoforms in hypoxia-tolerant carp indicates tissue-specific protective roles. Am J Physiol Regul Integr Comp Physiol 2012, 302:R693-R701.

18. Flogel U, Godecke A, Klotz LO, Schrader J: Role of myoglobin in the antioxidant defense of the heart. Faseb J 2004, 18:1156-1158.

19. Bickler PE, Buck LT: Hypoxia tolerance in reptiles, amphibians, and fishes: life with variable oxygen availability. Annu Rev Physiol 2007, 69:145-170.

20. Sun S, Sono M, Wang C, Du J, Lebioda L, Dawson JH: Influence of heme environment structure on dioxygen affinity for the dual function Amphitrite ornata hemoglobin/dehaloperoxidase. Insights into the evolutional structure-function adaptations. Arch Biochem Biophys 2014, 545C:108-115

21. Chen W, Wang X, Deng C, Lv X, Fan Y, Men J, Liang C, Yu X: Molecular cloning and characterization of a novel ras-related protein (rap2) from Clonorchis sinensis. Parasitol Res 2011, 108:1021-1026.

22. Liang C, Hu XC, Lv ZY, Wu ZD, Yu XB, Xu J, Zheng HQ: [Experimental establishment of life cycle of Clonorchis sinensis]. Zhongguo Ji Sheng Chong Xue Yu Ji Sheng Chong Bing Za Zhi 2009, 27:148-150.

23. Wang $X$, Chen W, Huang $Y$, Sun J, Men J, Liu H, Luo F, Guo L, LV X, Deng C, Zhou C, Fan Y, Li X, Huang L, Hu Y, Liang C, Hu X, Xu J, Yu X: The draft genome of the carcinogenic human liver fluke Clonorchis sinensis. Genome Biol 2011, 12:R107.

24. Weber RE, Vinogradov SN: Nonvertebrate hemoglobins: functions and molecular adaptations. Physiol Rev 2001, 81:569-628.

25. Rashid AK, Van Hauwaert ML, Haque M, Siddiqi AH, Lasters I, De Maeyer M, Griffon N, Marden MC, Dewilde S, Clauwaert J, Vinogradov SN, Moens L: Trematode myoglobins, functional molecules with a distal tyrosine. J Biol Chem 1997, 272:2992-2999.

26. Cho PY, Lee MJ, Kim TI, Kang SY, Hong SJ: Expressed sequence tag analysis of adult Clonorchis sinensis, the Chinese liver fluke. Parasitol Res 2006, 99:602-608.
27. Hong SJ, Lee JY, Lee DH, Sohn WM, Cho SY: Molecular cloning and characterization of a mu-class glutathione S-transferase from Clonorchis sinensis. Mol Biochem Parasitol 2001, 115:69-75.

28. Bae YA, Kim SH, Lee EG, Sohn WM, Kong Y: Identification and biochemical characterization of two novel peroxiredoxins in a liver fluke, Clonorchis sinensis. Parasitology 2011, 138:1143-1153.

29. Cai GB, Bae YA, Kim SH, Sohn WM, Lee YS, Jiang MS, Kim TS, Kong Y: Vitellocyte-specific expression of phospholipid hydroperoxide glutathione peroxidases in Clonorchis sinensis. Int J Parasitol 2008, 38:1613-1623.

30. Sies H: Strategies of antioxidant defense. Eur J Biochem 1993, 215:213-219.

31. Ferret PJ, Soum E, Negre O, Fradelizi D: Auto-protective redox buffering systems in stimulated macrophages. BMC Immunol 2002, 3:3.

32. Trachootham D, Lu W, Ogasawara MA, Nilsa RD, Huang P: Redox regulation of cell survival. Antioxid Redox Signal 2008, 10:1343-1374

33. Bruschi F: Modulation of inflammatory cells in helminth infections. Ann Ist Super Sanita 1997, 33:541-549.

doi:10.1186/1756-3305-7-250

Cite this article as: Ren et al:: Molecular characterization of Clonorchis sinensis secretory myoglobin: Delineating its role in anti-oxidative survival. Parasites \& Vectors 2014 7:250.

\section{Submit your next manuscript to BioMed Central and take full advantage of:}

- Convenient online submission

- Thorough peer review

- No space constraints or color figure charges

- Immediate publication on acceptance

- Inclusion in PubMed, CAS, Scopus and Google Scholar

- Research which is freely available for redistribution

Submit your manuscript at www.biomedcentral.com/submit
C Biomed Central 